\section{Robert Whitton}

is Managing Director of the Research \& Engineering Council of NAPL, a national association of leading companies in US graphic communications, as well as Principal of Arellton Group, $L L C$, where he consults in the area of operations and supply chain management for clients in printing, publishing and direct marketing. He is a member of the Marketing Technology Council of the Direct Marketing Association.
Keywords: variable data, VDP, personalised, cross-media, print, internet, website, e-mail, laser, inkjet, software, advertising, service provider
Robert Whitton

Research \& Engineering Council of NAPL

PO Box 284, Ridgefield CT 06877, USA

Tel: +1 2034380810

Fax: +1 2034313719

E-mail: BWhitton@napl.org

\section{Campaign execution: New technology platforms offer multichannel solutions}

\author{
Robert Whitton
}

Received: 30 October 2008

\begin{abstract}
This paper reviews the development of cross-media tools and techniques for direct marketers, with a healthy mix of personalised website, e-mail and print outreach to customers and prospects. By examining new and emerging approaches to customer messaging and marketing - illustrated through the narratives of active, current practitioners - the paper introduces an infrastructure and resources model for executing successful integrated marketing campaigns.

Journal of Direct, Data and Digital Marketing Practice (2009) 10, 233-248. doi:10.1057/dddmp.2008.40
\end{abstract}

\section{Executive summary}

\section{Background}

For the better part of the last 50 years, marketers and their clients have been reaching customers and prospects by way of targeted direct mail. Solo mailings to business and consumer addresses were personalised at the outset because of access to highly structured mainframe databases, obscure code for defining Cartesian 2-dimensional geometry, tape-driven metal or hot laser line printers, and an array of finishing and bindery-lettershop tools. With more sophistication, marketers learned to pre-print 'shells' in colour (sheets or rolls) and present static colour images and black and white text to the batteries of printers for the 'fill in the blanks' personalisation we grew up with, going beyond simple name and address information to include other customer data, list enhancement data, product data and more.

In the 1960s, it became possible to introduce vector and grey scale images as variable data elements (state or local maps, logos, product shots, stock images) alongside static selling copy or customer billing, thanks to advances in inkjet (small million-dollar add-ons to web printing presses), or offline inkjet and hot laser imagers surprinting the shell (sheets, fanfold or rolls).

In the 1980s, mail-merge came to office or departmental computing. And in the 1990s, along with the advent of the Graphical user interface (GUI) personal computers and the democratisation of desktop colour computers and monitors, the composition and personalisation software 
History

\section{Going forward}

became more flexible and sophisticated, so that both spot colour and the full range of colour (RGB or CMYK) were made available on office- and factory-compatible laser imagers.

The rise of the internet created all-new opportunities for companies, agencies and marketing service providers to reach customers with speed and economy, not to mention the same creative values (albeit restricted to a screen or cut-sheet printer), previously the exclusive domain of print direct mail.

Outbound telemarketing attracted a slew of regulation, in an era of privacy concern in the developed world. Against a backdrop of rising paper and postage costs, personalised website or e-mail marketing are so seductive that companies throughout the supply chain have invested millions over the last five years. This has taken the form of building capabilities for customer relationship management (CRM), transactional printing and customer acquisition that bridges several developed technologies, hitch-hikes with emerging technologies (mobile) and reaches the marketplace at a time and in a medium convenient to any recipient.

\section{Premise for today's marketer}

The case studies we will describe have four common elements:

- a supply chain, from one to many participants, representing the client, an agency, various marketing service providers including call centers;

- traditional media platforms for ink- or toner-on-paper reproduction (pre-press, approvals, digital imaging, web or sheet-fed offset ${ }^{1}$ );

- a set of eTools for hosting and delivering campaigns that involve the web, e-mail and a growing array of portable communications devices;

- the software and information technology (IT) capability to generate and archive data, offer creative solutions for any and all output devices, personalise, automate workflows, use analytics to capture results and trigger successive efforts in a campaign, fulfill goods and services, and pre-sort to qualify for lowest delivery and postal rates.

At the nexus of these four ingredients lie the stories that bring to life the integrated marketing and messaging capabilities discussed above. We will emphasise for economy those hardware and software tools that are creating the greatest stir in our, and several other industry verticals, offering the strongest argument for the adoption and expansion of best practices in integrated marketing execution.

\section{Supply chain}

Who are the participants in an integrated marketing campaign? And how do they interrelate with each other?

In the advertising agency model, the wheelhouse for strategy and decision-making, procurement of third-party services is in the creative 
and media buying domain. Sometimes this is fraught with peril. One large US-based utility has four agencies of record serving six lines of business, all of which share a sophisticated print services provider. It will surprise no one that lack of knowledge and coordination, even in the face of strong results from highly variable marketing campaigns, is the factor that most distinguishes the enterprise's Go To Market strategy.

On the other hand, the ultimate client drives campaign execution. In this case, they may have reasons such as data security (financial services or pharmaceutical) not to delegate functions to other business entities, and may themselves, directly, announce availability of e-statements or mail paper statements of account status to customers. The same kinds of firms often do, with proper safeguards, award list work, design-creative, Variable Data Printing (VDP) programming, web hosting, eblasting, product-sample fulfillment, and variable print and mail to fully vetted suppliers.

Print service providers often develop and sell concepts through

\section{Business models} execution. The best of them - we will call them marketing service providers - go on to play an active role in list handling and selection, analytics, results measurement and reporting, telemarketing and a good many other functions that have been bundled together as a total package by their customers. When the customer has sufficient size, scale and leverage, some of the tasks may be assigned to another contract supplier or agency boutique. But the siren call of 'one stop shop' and full accountability (not to mention share of wallet and profits for the supplier) is quite strong, and this is a very robust model, though overall in its infancy.

Firms in this latter group have many different antecedents. Some originated as design-creative firms. Others came from a pre-press heritage. Still others from traditional commercial printing or the highvolume mail service provider ranks. Others may be in the corporate Business Process Outsourcing game, and may manage data centres for key clients that evolve to large document solutions shops with a significant breadth of services. A few came together as a result of a founder's 'Big Idea,' and find clever ways of going to market without the historical baggage or biases that might inform the choices of operational execution. Thus, latent competitors come to embrace assignments that heretofore existed in traditional industry verticals or for that matter not at all.

Not surprisingly, in order to hone their skills and build awareness and understanding of the power of integrated marketing, many firms start out as their own client, and use the tools to drive customers to executive seminars, exhibit floor demos, open houses, White Paper downloads and other opportunities to evangelise and spread the good word.

Interestingly, one digital press manufacturer, InfoPrint Solutions US, a merger of effort by IBM and Ricoh, runs a marketing and print shop incubator, developing proof of concept multi-channel campaigns including all the peripheral disciplines (segmentation, design, analytics 


\section{Printing advance}

and several outbound customer-facing technologies) to meet the needs of a high-potential client. At the same time, like others, they offer tutorials and guidance on making a financial success of their highvolume black and white or full-colour equipment, both pre- and post-sale, with the result that, ideally, the client experiences the promised return on investment.

Born of that experience, many providers come to know that ideation, brainstorming, consultative selling and formal project management are the most successful ways to collaborate in the strategy, design and execution of multi-effort cross-media campaigns. Collaborating with marketers and C-level decision-makers makes them that much more valuable and likely to succeed at the desired solution.

\section{Print media}

Most variable printing in developed countries revolves around a combination of lithography (pre-printed 'shells') and black and white digital imaging, which is the old business model. Indeed, for long-run work, or work that is 'somewhat' variable, many firms have highly sophisticated digital portals and storefronts, highly automated imposition and gang-run-planning software, and even databases of 'clip art' design elements or company-proprietary images and fonts. These permit consumers and business users to deliver marketing intent, design and content to a few networked platemakers or Raster Image Processors (RIPS) and sheet-fed or web presses — offset litho and digital. Today, many MAN Roland (Germany), Komori (Japan), Heidelberg (Germany), Muller Martini (Switzerland), Drent Goebel (Netherlands) and Sanden (Canada) presses prepare or deliver finished and partially finished work to the addressing, bindery and shipping area. A multinational standard for Job Definition Format allows not only content, but also job specifications to be routed throughout the enterprise, down to individual production centres such as presses and finishing equipment.

More impressive of late, many sheet-fed and web digital platforms are going beyond just adding black or spot-colour variable overprint to full-colour digitisation. These are the so-called White-Sheet-of-Paperto-Mail methodologies. Just as new wider, faster offset print platforms have the ability to replace more than one piece of legacy equipment on a modern print factory floor, so also can high speed, mid-to-highquality-toner-based or inkjet colour imagers replace multiple sheet-fed imagers and, carried to the logical conclusion, replace the now-legacy offset equipment and the warehouses they fill. Steps, touches, costs and cycle times are reduced. Job set-ups are accomplished via a stream of all digital instructions and content, and in some cases final finishing of the self-mailer, booklet, postcard or catalogue cover can be significantly automated and brought near-line or in-line with the reproduction process.

Print imaging companies with a significant stake in the outcome are Océ (Netherlands), whose 500 feet per minute (152 meters per minute) 


\section{Digital imaging}

full colour inkjet, JetStream 2200, debuted in North America this year to create rapid turn-around trigger mailings for consumer-based financial services companies. Océ has a significant presence in roll-fed, industrial strength black and white laser printers for direct marketing and statement printing.

Kodak (US) brought machine number 1 of its Stream continuous inkjet colour technology to the DRUPA print show in Düsseldorf last spring, and promised similar, high-speed throughput at resolution approaching 175 lines per inch (approximate resolution 70). The NexPress line of laser toner machine has been a commercial-quality cut-sheet full colour staple for many years.

Another recent entrant is from HP, the Inkjet Web Press, capable of duplex imaging a 30 -inch $(762 \mathrm{~mm})$ roll at 400 feet per minute (122 meters per minute) and as high or higher resolution than Kodak. HP (US) has an extensive line of high-quality laser-powered Indigo machines much used in label printing and direct marketing.

InfoPrint targets its up to 210 feet per minute (64 meters per minute) colour inkjet IP5000 at data centres and direct marketing, with IBM's Advanced Function Printing (AFP) formatted data stream for find-a-needle-in-a-haystack uncompromised high-security printing.

Xerox (US), with a full pipeline of black and white and colour toner-based laser machines used in many direct marketing environments (the crown jewel is the new iGen4), has added all sorts of automation and colour fidelity to its almost 200 feet per minute ( 57 meters per minute) 4-colour cut-sheet machine. The company enjoys a sizable share of the early-adopter CRM variable print market, combining the DocuColor and iGen3 printer lines.

Several other deep-pocketed image printer companies, for example Fujifilm, Punch-Xeikon, Screen and AGFA, have brought good-quality high-capacity machines to market, with the result that marketers and their outsource print partners are becoming 'spoiled for choice', which is a good thing for the ultimate customer.

\section{Software}

The tools available to marketers and service providers have never been more robust. Some are broad and deep in scope, whereas others are point solutions to specific opportunities facing practitioners. In the early days, a good deal of what people utilised were locally, purpose-built proprietary applications. For example, many of the early web portals were constructed by service providers for their own and clients' use. Today, a good many off-the-shelf capabilities can be purchased or licensed and integrated into a marketing workflow.

In the area of portals, still, some of the ubiquitous implementations rely on ASP architecture, and the hosted solutions are available from US companies such as Printable and MindFire, known for its PURLs (personalised URLs) and InterlinkONE. Other US-headquartered contenders such as EFI, Kodak and PageFlex (Bitstream) are usually installed behind the firewall on local file servers, and may be more 


\section{Software tools}

readily integrated into a full portfolio of integrated marketing tools. A good number of print service providers built their own web portals; a number of these are still in service and are even being upgraded to match the ever-changing, special needs of their developers.

Inevitably, a good many such programmes were developed at the outset to support traditional print (both static and variable content). And in some cases, the main purpose of the browser-based front door to the enterprise was to permit brand managers access to corporately controlled graphical and text assets and deploy them using online composition for geographically dispersed marketing collateral and campaigns.

Gradually, more sophisticated data storage came into play. These were not just print-ready documents, but also elements that could be repurposed to any delivery channel on the fly with greater and greater customisation and personalisation. Forms imaging software such as Printsoft (Australia) and ISIS (Austria) came to mean either/or/both print and electronic PDF bills and statements made available to customers of utilities, banks and brokerage houses.

Firms such as GMC (Switzerland), whose roots are in high-volume personalisation, have extended their capabilities so that the web browser point of entry (and personalised form or e-mail point of departure) has more tightly embraced their traditional user group.

Finally, marketing automation products such as Aprimo (US) have extended their product offering to include outbound e-mail (or links to call centres) in the group of activities that marketers can control from a sophisticated dashboard for campaign management.

To make the software useful in a cross-channel marketing environment, other developers combined personalisation (for print, the web, other digital communications channels) with a strong digital asset management resource. Exstream, purchased by HP last spring comes to mind. A similar but different set of products from Saepio (US) are in both mature and 'trial balloon' stage (watch for mobile messaging technology announcements in the fall and winter of 2008).

From the creative vantage point, many of the technology providers listed above provide template design capability for multiple media, so that users have only to look within the application suite for most or all of what they require in terms of text and graphic design. Indeed, PageFlex comes from a strong heritage of font design and composition. XMPie, owned by Xerox, brings graphic arts pre-press background to an Adobe-compatible platform, so that both Dreamweaver and InDesign form the underlying architecture for an XML-based set of user tools for database management, design and formatting for multichannel output.

One niche provider of arresting visual personalisation is DirectSmile (Germany). In addition to allowing users to build web landing pages and handle PURLs, DirectSmile's award-winning software, coordinated with Adobe InDesign page layout software and the Adobe Creative Suite, provides unique graphical personalisation that integrates with full-service software platforms from the digital-equipment-makers, 


\section{Poland Transpromo}

\section{Mixed Media}

RIPS, workflow, digital asset management (DAM) and variable data print engines.

\section{Successful implementations}

There are numerous examples of marketing or content/messaging campaigns driven by cross-media outreach to customers and prospects. Let us highlight a few of them.

\section{Colour Transpromo springboard to multimedia}

In Warsaw, Poland, a nine-year-old privately owned firm, Inforsys, employs 150 and has grown 20 per cent-plus annually for the past three years. The business model is marketing communications, statement-rendering and a good amount of Transpromo work, chiefly organised around HP's Exstream software, workflow engines from mailing equipment vendor Pitney-Bowes, a good deal of home-grown communications and portals, and the print content variability that comes from 100 per cent reliance on black and white and full-colour tools from Xerox, IBM and Kodak (the Versamark high-speed colour predecessor to Stream technology mentioned above). Design and layout is outsourced. Banks (such as Deutsche Bank and Santander) primarily drive the colour-variable Transpromo work, and Inforsys plans to build out from its present testing and marketing efforts to multichannel communications and nontraditional media in 2009.

\section{Direct mail, PURLs and e-mail}

Proven Direct is a rapidly growing marketing production company with a clientele of regional and national firms close to its Milwaukee, Wisconsin (US) location. This firm transformed itself from a traditional mail services provider to a platform of five HP Indigo variable colour imagers, PageFlex software for building custom web portals and MindFire software to create Personalised URLs, track and manage results of customised outbound electronic messaging. A third-party alliance partner does outbound telemarketing and in the process performs list hygiene (Figures 1 and 2).

More than 60 per cent of the time, campaign planning and strategy typically involve the company's active participation beginning with the concept itself. PURLs either result in hits on a Proven Direct site or on the client's website. A mix of electronic and paper mail communications, along with iterations, usually results in a phased follow-up to responders, to those who selected the hyperlinks but did not leave a landing page and to non-responders.

There is no set template for PURL landing pages (sometimes surveys, sometimes not) and the company sells the power of the PURL not so much for lift in response outright as for a viable alternative to Business Reply mail turnaround documents, along with valuable measurement and reporting. An American competitor argues that the primary objective is not so much to lift response as to obtain and mine customer data. Proven Direct proselytising involved a number of client 


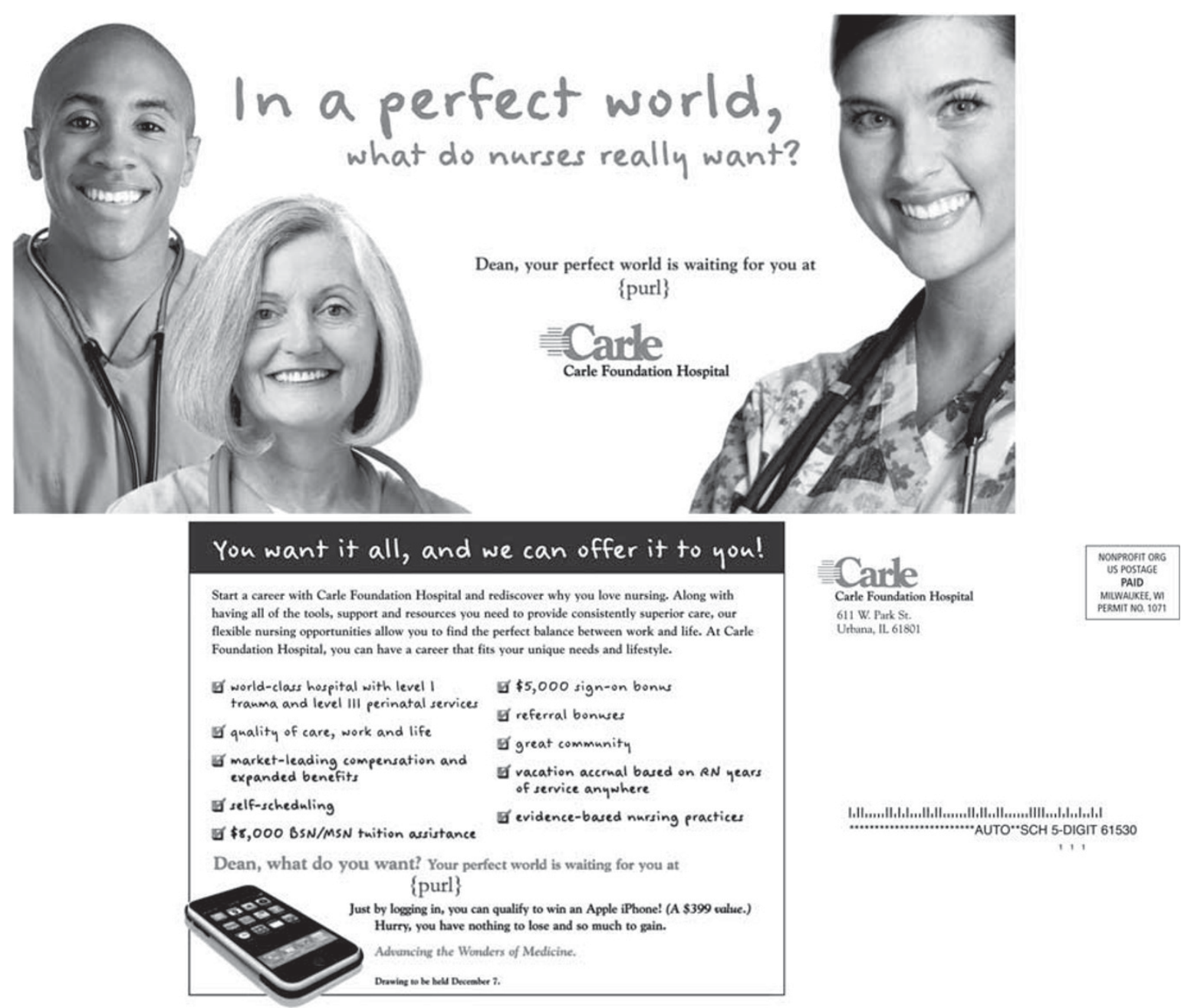

Figure 1: University admissions, Proven Direct, Milwaukee, Wisconsin, html landing page

on-site executive seminars to go from awareness to buy-in among their healthcare, banking, insurance and education customers.

\section{Mix of web, direct mail, e-mail and list segmentation}

Across the border in Guelph, Ontario (Canada) is a six-year-old consultancy-agency called Blue North Strategies. Their primary objective is communications effectiveness (and some up-front production) for financial services and fundraising nonprofit entities, and about one quarter of the campaigns they touch are cross-media efforts. For their financial services clients, Blue North deliver the communications strategy, messaging, rules, specifications and Transpromo designs for the customer to execute via its high-volume service providers.

For a global nonprofit disaster relief agency, Blue North employ an array of high-touch tools and disciplines to approach donors of every 


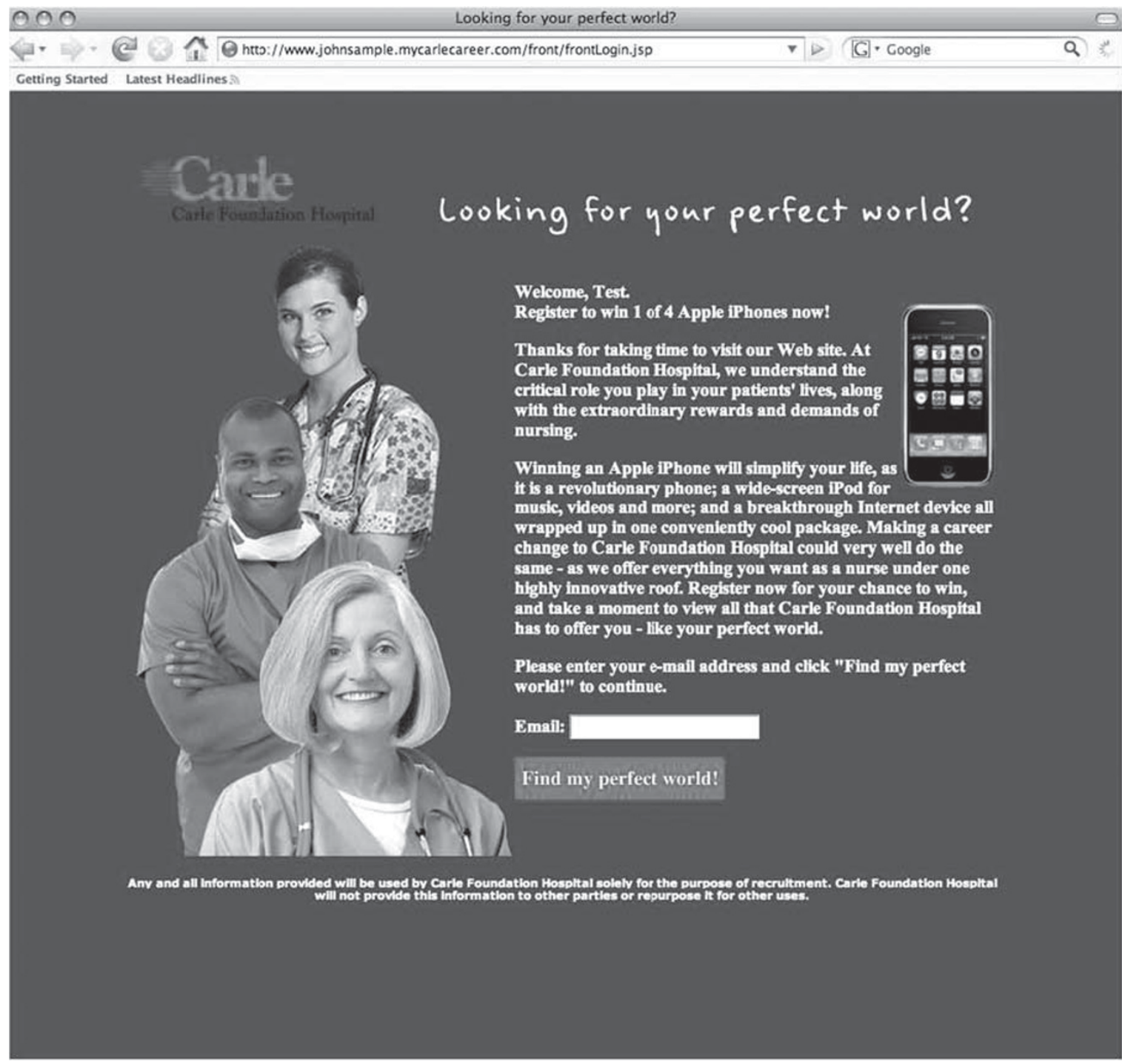

Figure 2: University admissions, Proven Direct, variable text postcards with PURLs

type. The off-the-shelf software comes from HP's Exstream Dialogue product, though Blue North has supplemented this with a good deal of custom-built integration for e-mails and customer-facing web applications. Variable templates are built before disaster strikes regions served by WorldVision, and some offset 'shells' are pre-printed and held in inventory by Blue North's printer, so that at a moment's notice boilerplate and variable text and images can be merged into direct mail formats for release to a segment of the donor base. The same 'pending disaster' approach to advance template building is used for e-mail blasts (Figures 3 and 4).

Donors drawn to landing pages will see two-dimensional text and graphics alongside video appeals. Where the appeal is handled by WorldVision's own outbound telemarketing advisers, Blue North 


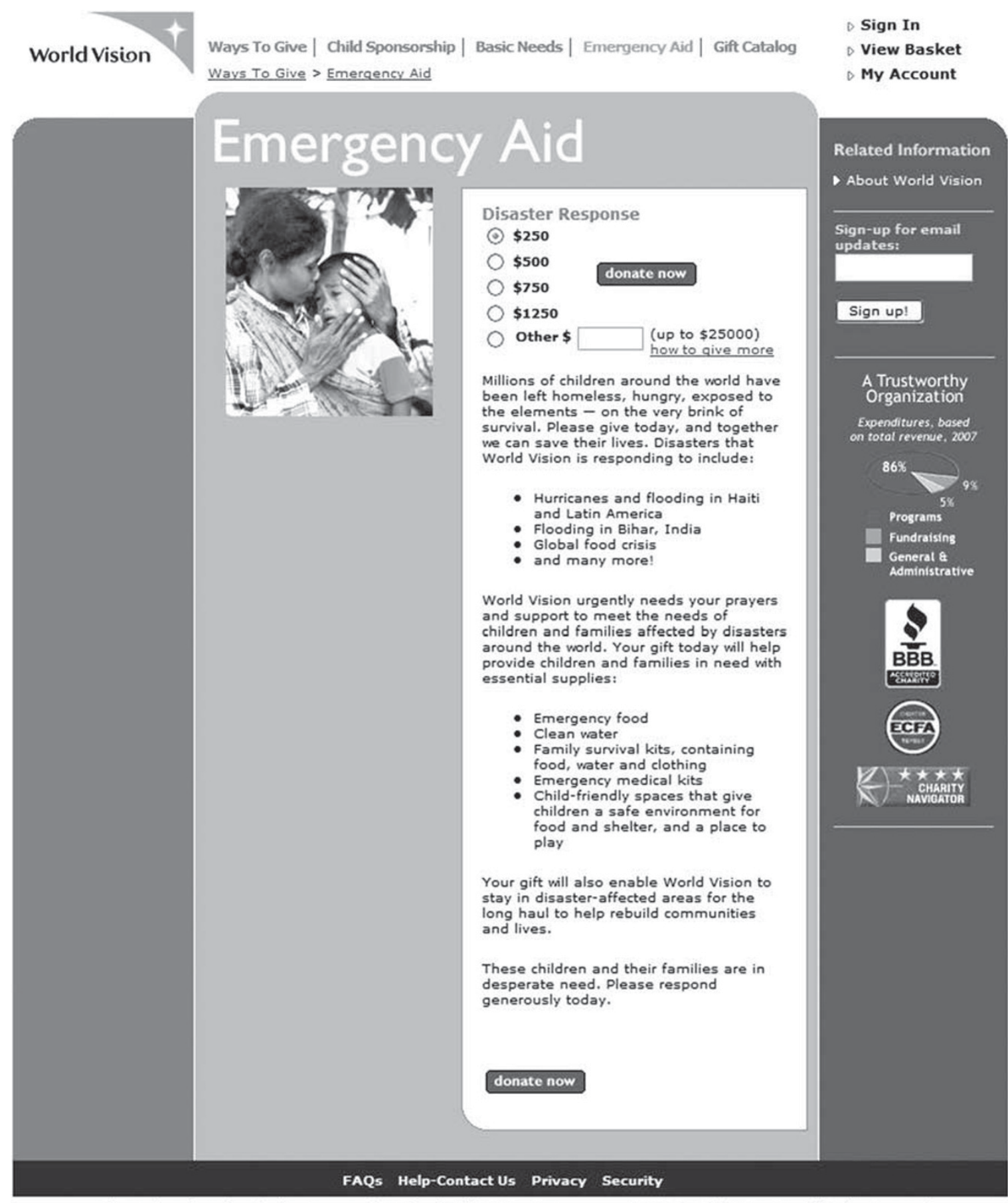

The trademarks referred to herein are trademarks of World Vision, Inc.

(3) 2008 World Vision, Inc. All Rights Reserved

Figure 3: Charity solicitation, Blue North Strategies, website landing page

provides materials, scripts, talking points and an 'ask' strategy. They also put up an extranet for WorldVision staff to consult regarding optional approaches to top donors. A future build-out of capabilities allows clients such as WorldVision to use a self-serve personalisation portal to extend the sophistication and targeting of the approach. 


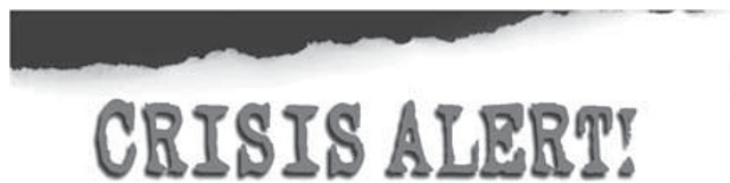

World Vision

\section{CYCLONE SLAMS MYANMAR}

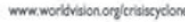

$\mathrm{x} \operatorname{xxxxxxx}$

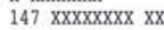

CHINA GROVE IC 28023

May 7, 2008

Dear Partner,

Tropical Cyclone Nargis has left at least 22,000 dead in Myanmar, with the death toll expected to soar. Up to one million are homeless. Those who survived the deadly storm are living in desperate conditions - in hard-hit areas, nearly 95 percent of homes are damaged or destroyed. It is estimated that as many as 2 million people in total will be affected by this cyclone, the biggest to strike Asia since 1991.

When disaster strikes, it is children who are most vulnerable. The most critical needs in Myanmar are for clean water, food, and shelter. As one of only three agencies asked by the Myanmar government to respond to this crisis, World vision is working hard to meet these needs and save children's lives. We urgently need your help today to support our emergency relief effort in Myanmar.

Our emergency teams on the ground have already distributed $10,700 \mathrm{kgs}$ of rice and 7,400 litres of water, plus survival kits containing clothing, tarpaulins, and

blankets. Our 30-day response plan targets 250,000 people. We are preparing an airlift of energency supplies such as food, water

continued) Thousands need your
help. Please act now! Give online at www.worldvision.org/ crisiscyclone

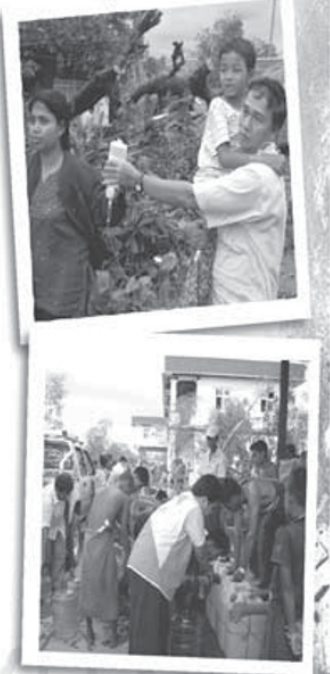

Yes, Rich! Please RUSH my gift to help people in Myanmar now!

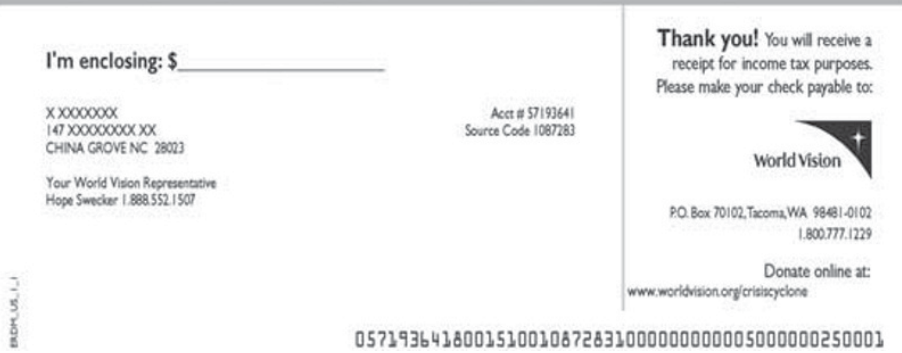

Figure 4: Charity solicitation, Blue North Strategies, direct mail letter

Facsimile, CD-ROM, SMS, direct mail, e-mail and hosted websites Located outside London (UK), dsicmm group's Nexdox facilities are home to a well-equipped group of Xerox iGen (eight of them), 


\section{Sophistication and complexity}

\section{With traditional media}

DocuColor, InfoPrint 5000 colour-variable imagers, multiple web and cut-sheet black and white laser machines, and a completely bespoke system to drive them as well as all of the other nonprint media required by its financial services, retailing, holiday travel and other clients, facsimile, website hosting, PURLs, e-mails, any-format-you-like archives of client and ultimate customer records, CD-ROM, SMS the list is impressive.

This data powerhouse started innocently enough 15 years ago in international mail, migrated to postal pre-sort, then print managementbrokerage, and ultimately to a five-location, 1,200-employee firm with creative development, project management, customer service (CRM Team) and substantial IT resources. A robust, proprietary Swiss Army Knife suite of utility software is at once a 'universal recipient' and 'universal donor' for receiving client and third-party marketing data as well as generating every conceivable output. Sixty full-time IT developers provide system and campaign support for cross-media marketing campaigns where dsicmm takes full responsibility, as well as those where they collaborate with major direct marketing ad agencies.

The systems were put to a test in spring 2006 during the run-up to the quadrennial IPEX print show in Birmingham. After list selection and segmentation, three groups of postcards with PURLs were sent to 70,000 Xerox customers and prospects around the world. DSI hosted the website landing pages, captured IPEX attendance information, produced up to 169 different personalised fullfillment packs and provided their client, Xerox, with detailed, up-to-the-minute scheduling, attendance, and customer interest information. The show was a great success measured by sales booked on-site (Figure 5).

\section{Coordinated broadcast media with timed post cards, PURLs and client-redirected website}

Pawtucket, Rhode Island (US) is home to 55-year old Mercury Print \& Mail, a full-service marketing communications firm specialising in planning through post-production analysis of targeted promotions. Beginning in 2007, they worked with a local semi-professional baseball franchise, the Pawtucket Red Sox, related to its neighbour to the north the Boston Red Sox, to drive subscription ticket sales and merchandise offerings (Figure 6).

Working closely with client management and tie-ins to newspaper, television and radio advertising, Mercury used their MindFire and XMPie software to build PURLs, populate custom websites for each prospect and drive them to a landing page using oversized variable postcards imaged on their Xerox DocuColor 7000 imager. With just a click, ticket buyers were redirected to the 'Purchase Now' submit button and then on to the PawSox main site. The mailer, whose timing in-home was calibrated to the proximity of recipients to Pawtucket, achieved a 3.5 per cent total response - 40 per cent of the respondents went on the website and purchased one or more \$95 Fan Packs for the season. The PawSox campaign achieved a 500 per cent return on 
a
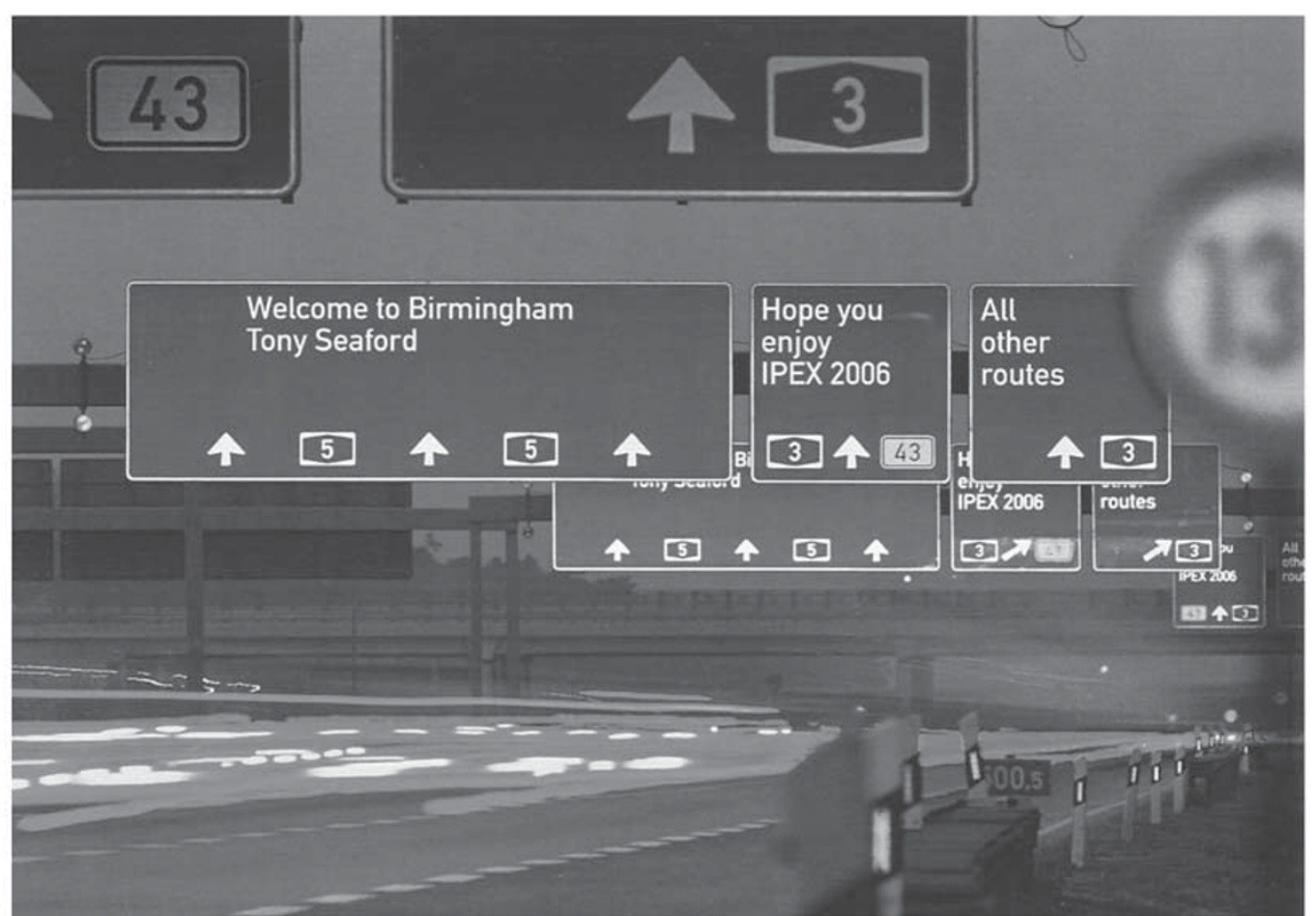

b

\section{WIJ HEBBEN ALLES VOORBEREID OM OP IPEX 2006 EEN ZEER BELANGRIJKE GAST TE ONTVANGEN... U!}

Tony Seaford, kom als gast van Xerox naar IPEX 2006 en zie met eigen ogen wat digitaal printen allemaal voor $u$ kan betekenen.

De grootste beurs voor de grafische industrie in de Engelstalige wereld vindt van 4 tot en met 11 april 2006 plaats in de NEC in Birmingham (GB). En graag willen wij u hiervoor uitnodigen als gast van Xerox.

Meer dan $5.000 \mathrm{~m}^{2}$ met tal van ideeën en het allernieuwste op het gebied van digitale printtechnologie.

Dit jaar laten wij onze nieuwste producten, workflowoplossingen en business tools zien in de grootste stand op de beurs, die meer dan $5.000 \mathrm{~m}^{2}$ beslaat.

$\mathrm{Wij}$ zijn ervan overtuigd dat $\mathrm{u}$ bij ons alles vindt wat $u$ moet weten over indrukwekkende nieuwe toepassingen en de toekomst van digitaal printen.

llet enige wat $u$ hoef te doen om uw gratis toegangsbewijs voor IPEX te ontvangen, is het invullen van uw persoonlijke registratieformulier op www.xerox.com/ipex/Seaford0053

Wij begroeten u graag op IPEX 2006 en zijn ervan overtuigd dat uw bezoek aan de beurs uiterst aangenaam en zeer productief zal zijn.

\begin{tabular}{|c|c|}
\hline \multicolumn{2}{|c|}{ PRIORITY } \\
\hline 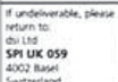 & $\begin{array}{c}\text { P.P. } \\
\text { Swiss Post } \\
\text { CH-8058 Zurich }\end{array}$ \\
\hline
\end{tabular}

Tony Seaford

1 AB Sample Street

AB Sample Town

Sample County

Sample Postcode

United Kingdom

HO-OSWUNOS001-16. VO1.VPS000128000025S/ - 1

Figure 5: Xerox at IPEX, dsicmm Ltd., London, England, postcard with PURL

investment (we should all be so lucky). As a result, Mercury Print \& Mail has pushed selling the strategy, planning, testing, VDP and PURLs-plus-analytics package to a number of other clients. The consensus seems to be that the measurement (and easy fulfillment) of 


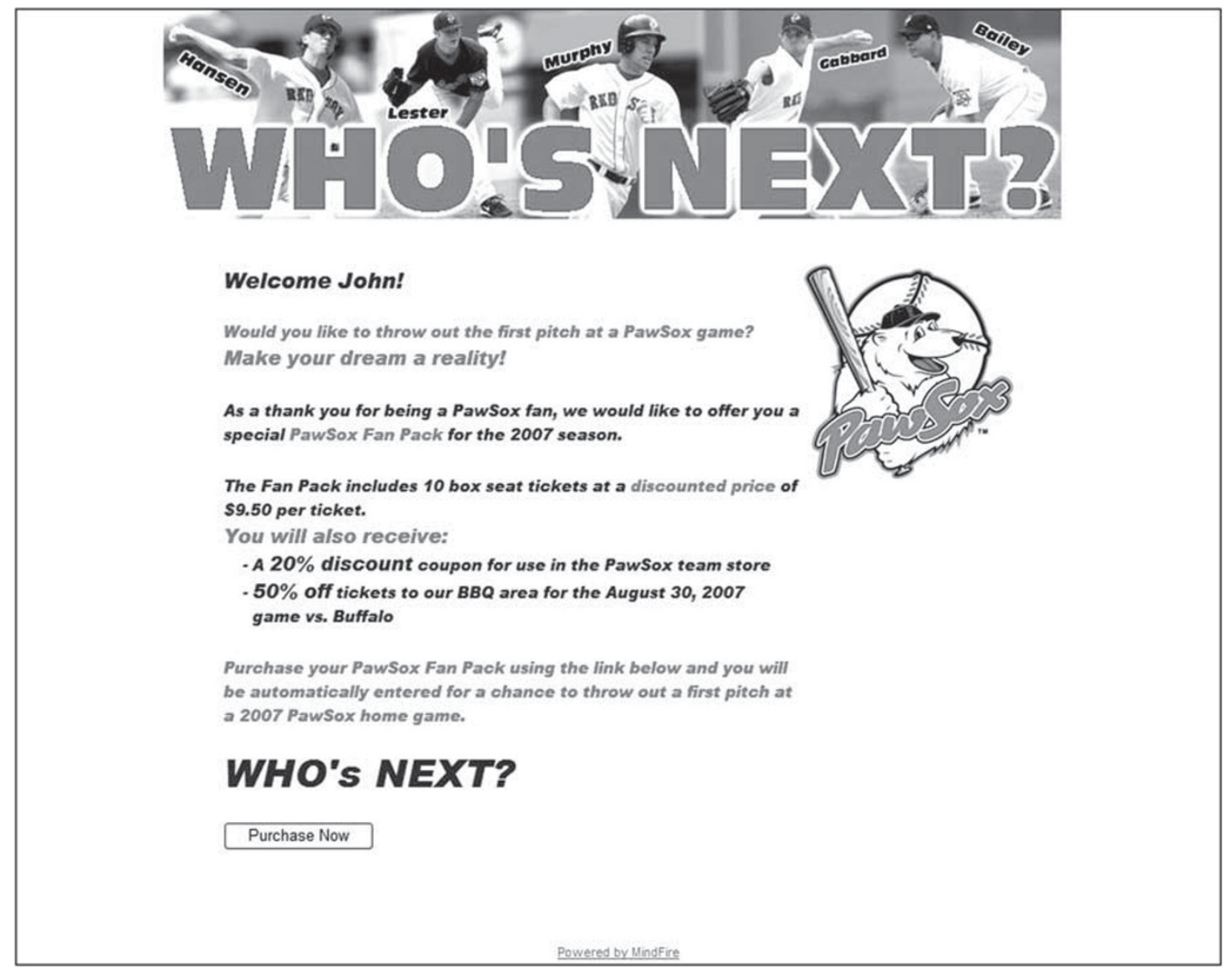

Figure 6: PawSox baseball ticket sales, Mercury Print \& Mail, Pawtucket, Rhode Island, web landing page

offers using a combination of mail and the internet is highly desirable when the market, as now, tightens.

\section{Summary}

Cross-media marketing works to achieve a variety of objectives, using an array of approaches, tools and disciplines. Sometimes marketers bring together a tight-knit collaboration of multiple organisations to attain the desired results. In other instances, the capabilities and controls devolve to a single provider.

Characteristically, most successful marketing service providers are fairly young business entities, blending tools from static print with technologies whose history dates to the internet and mobile communications explosion.

Cross-media marketing has reached the stage where the essential disciplines are creative, project management, technical and executional. Moreover, the arsenal of hardware, software, communications and storage technologies needed for flawless campaigns is accessible to giant utilities and small universities, large financial services firms and 


\section{Outlook}

\section{Note}

1. At least one high-volume printer in America makes money with flexography for the base print.

\section{Appendix}

A resource map for locating some of the technologies mentioned in this paper:

Companies cited by example

Blue North Strategies, www.bluenorth.ca

dsicmm group, www.dsicmmgroup.com

Inforsys S.A., www.inforsys.pl/en

Mercury Print \& Mail, www.mpmri.com

Proven Direct, www.provendirect.com

\section{Traditional high-volume manufacturers}

Drent Goebel, www.drent-goebel.com

Heidelberg, www.heidelberg.com/www/html/en/startPage

Komori, www.komori.com

MAN Roland, www.manroland.com/com/en/index.htm

Muller Martini, www.mullermartini.com/us/DesktopDefault.aspx/ tabid-209//75_read-105/

Pitney Bowes, www.pb.com

Sanden Machine, www.sandenmachine.com

JDF/CIP 4, www.cip4.org

Imaging technologies

AGFA, www.agfa.com/en/gs

Fujifilm, www.dimatix.com

HP, www.hp.com/country/us/en

IBM, www.infoprintsolutionscompany.com

Infoprint Solutions, www.infoprintsolutionscompany.com 
Kodak, http://graphics.kodak.com/US/Product/Printers_Presses/ default.htm

Océ, www.oce.com/en

Punch Xeikon, www.xeikon.com

Screen, www.screenusa.com/products.cfm/solution/variable_data Xerox www.xerox.com/digital-printing/digital-printing-press/engb. html

\section{Software providers}

Adobe, www.adobe.com

Aprimo, www.aprimo.com

DirectSmile, www.directsmile.de/index.php?id=363\&L=0

EFI, www.efi.com

Exstream, www.exstream.com

GMC, www.gmc.net

InterlinkONE, www.interlinkone.com

MindFireInc., www.mindfireinc.com

PageFlex, www.bitstream.com/publishing

Printable, www.printable.com

Saepio Technologies, www.saepio.com

XMPie, www.xmpie.com 